\title{
CTENOBETHYLUS (BETHYLIDAE) A NEW SYNONYM OF IRIDOMYRMEX (FORMICIDAE, HYMENOPTERA) ${ }^{1}$
}

\author{
BY WILLIAM L. BROWN, JR. \\ Department of Entomology, Cornell University \\ Ithaca, New York 14853
}

In 1939, in a paper describing several new genera and species of Baltic Amber Hymenoptera, C. T. Brues erected Ctenobethylus succinalis gen. et sp. nov. for a single specimen of what he took to be an apterous female bethylid. I recently chanced upon this description, and was immediately struck by the antlike habitus of the type as portrayed in Brues' fig. 7. It was also noted that the figure showed only 12 antennomeres, although Brues had made a diagnostic point of claiming "13-jointed" antennae for his genus.

My suspicion that the type of $C$. succinalis is actually a worker ant of the dolichoderine genus Iridomyrmex was confirmed when it was sent for my study. The specimen has the legs folded up so as to obscure the waist, which explains why Brues did not see the petiolar scale. In the preparation as it now stands, however, the scale is partly visible in a left-side view, although it is covered with a white film. The specimen also has 12-merous antennae, and in fact closely corresponds to small-sized workers of Iridomyrmex goepperti with which I have compared it directly.

Although I have not seen the type of I. goepperti, I compared 11 worker specimens of this commonest of all Baltic Amber ants lent from the Museum of Comparative Zoology collection. ( $I$. goepperti made up over half of the more than 10,000 Baltic Amber ants determined by W. M. Wheeler at one time or another; see Wheeler, 1914: op. cit. infra, p. 8.) These specimens and the $C$. succinalis type meet very well the available descriptions of I. goepperti. The formal synonymy is:

\footnotetext{
1A Report of Research from the Cornell University Agricultural Experiment Station. Research supported by National Science Foundation Grant DEB75-22427. Manuscript received by the editor November 16, 1976
} 


\section{Iridomyrmex goepperti}

H!poclinea göpperti Mayr, 1868, Beitr. Naturk. Preuss. 1: 56, pl. 1, fig. 3-7; pl. 3, fig. 42-46, worker, queen, male.

Iridomyrmex goepperti: Wheeler, 1914, Schrift. Phys-ökon. Ges. Koenigsberg, 55: 90-91, worker.

Ctenobethylus succinalis Brues, 1939, Ann. Entomol. Soc. Amer. 32: 261-263,

fig. 7, 9 (recte worker). Type: Museum of Comparative Zoology, Harvard

University, No. 7666. NEW SYNONYM.

Brues' figure errs in omitting the spurs, present one on each tibial apex, and also in showing the trunk as without an impressed metanotal groove; actually, this groove is distinctly though modestly impressed in the type.

I. goepperti is left in Iridomyrmex for the time being, although this genus is almost surely a diphyletic assemblage. The IndoAustralian species, including the type species of Iridomyrmex, I. purpureus ( $=I$. detectus), differ from the New World members (I. humilis group) in that they lack Pavan's apparatus (with gland) at gastric sternites IV and V. The status of the Baltic Amber Iridomyrmex with respect to this character has not been determined, because the few samples available to me have the underside of the gastric apex obscured by films. As already stressed by Wheeler, I. goepperti lacks a distinct epistomal (frontoclypeal) suture and frontal triangle, conditions atypical for Iridomyrmex (and for ants in general). It is likely also that the living species of Iridomyrmex divide further into groups on the basis of proventricular anatomy, position of compound eyes, larval morphology, karyotype, and perhaps other characters. If some of these groups represent different genera, as seems likely, we do not know yet how the divisions will cut, or what genus-level names are available.

The "Iridomyrmex Problem" is an exceptionally complex one, calling for nothing less than a full-scale revision of the Tapinomini. Until that revision can be made, the genus Iridomyrmex is best left as it stands, and Ctenobethylus, with type and sole species C. succinalis, is its new synonym.

In recent correspondence with E. O. Wilson and H. E. Evans, I learned that they had jointly examined Ctenobethylus succinalis several years ago, and tentatively considered it to belong to Iridomyrmex, but they did not complete the study. I am grateful 
for their opinions, but since the present study was made independently, they should not be held responsible for my conclusions. F. M. Carpenter has my thanks for the improved preparation and the loan of the $C$. succinalis type. 

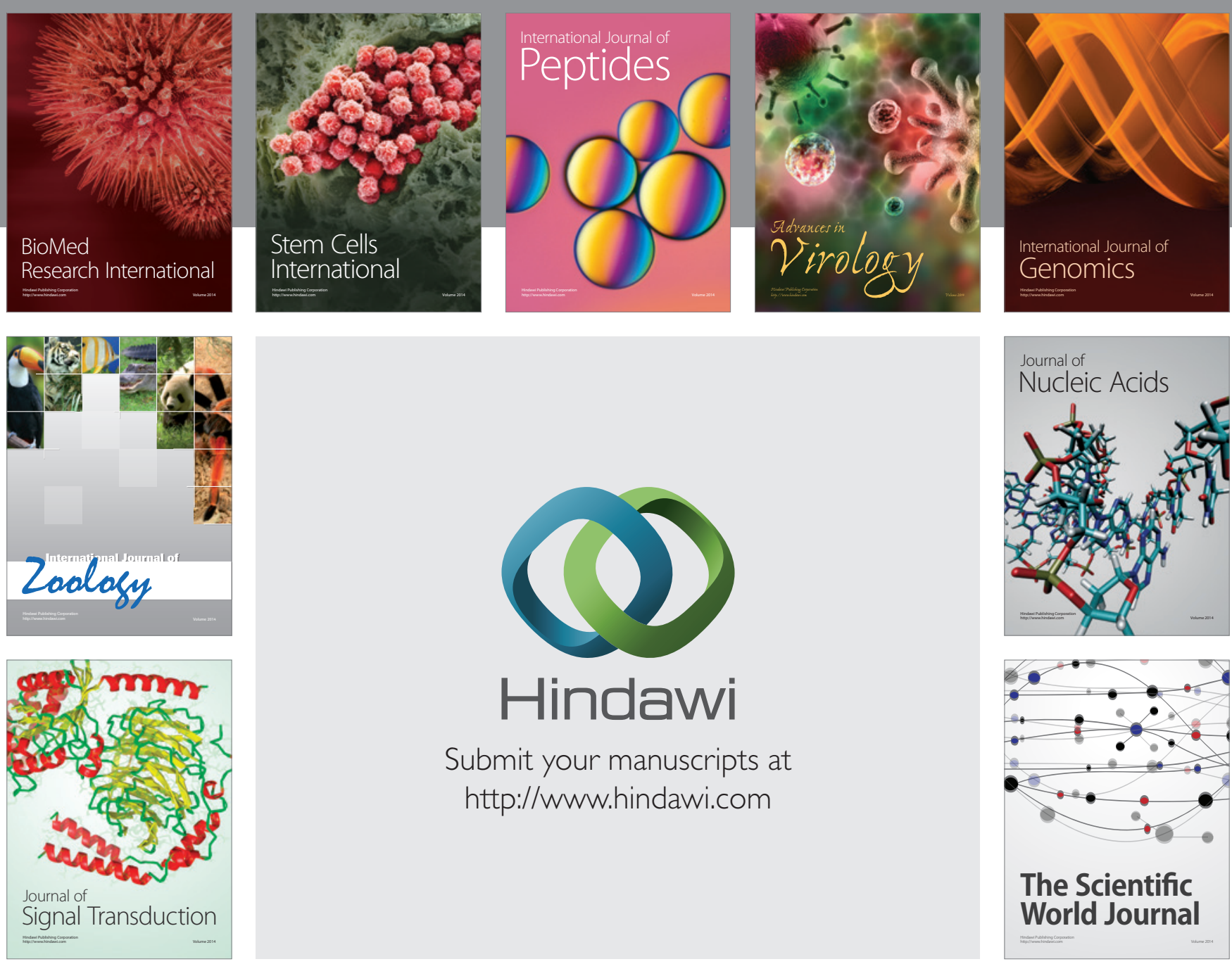

Submit your manuscripts at

http://www.hindawi.com
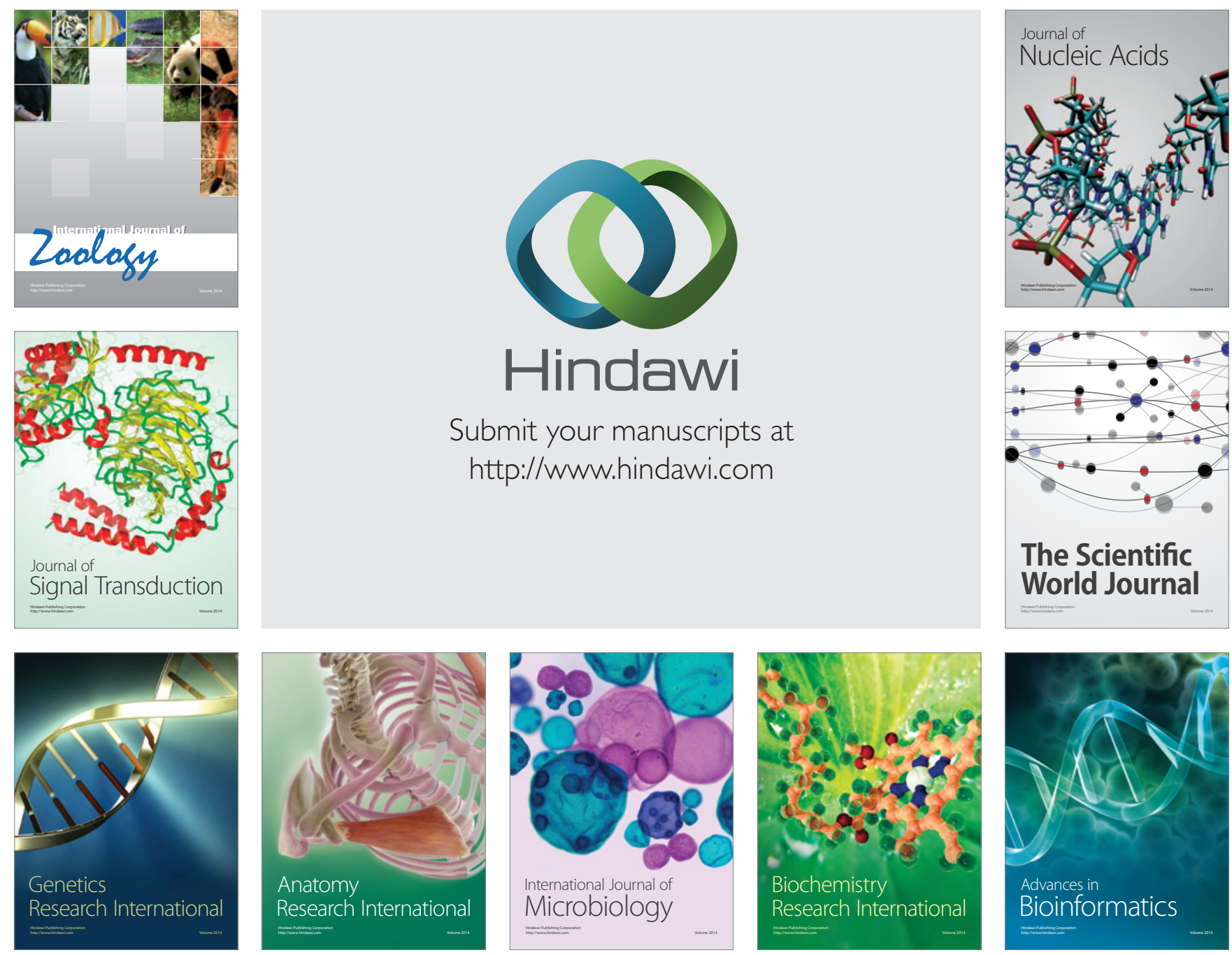

The Scientific World Journal
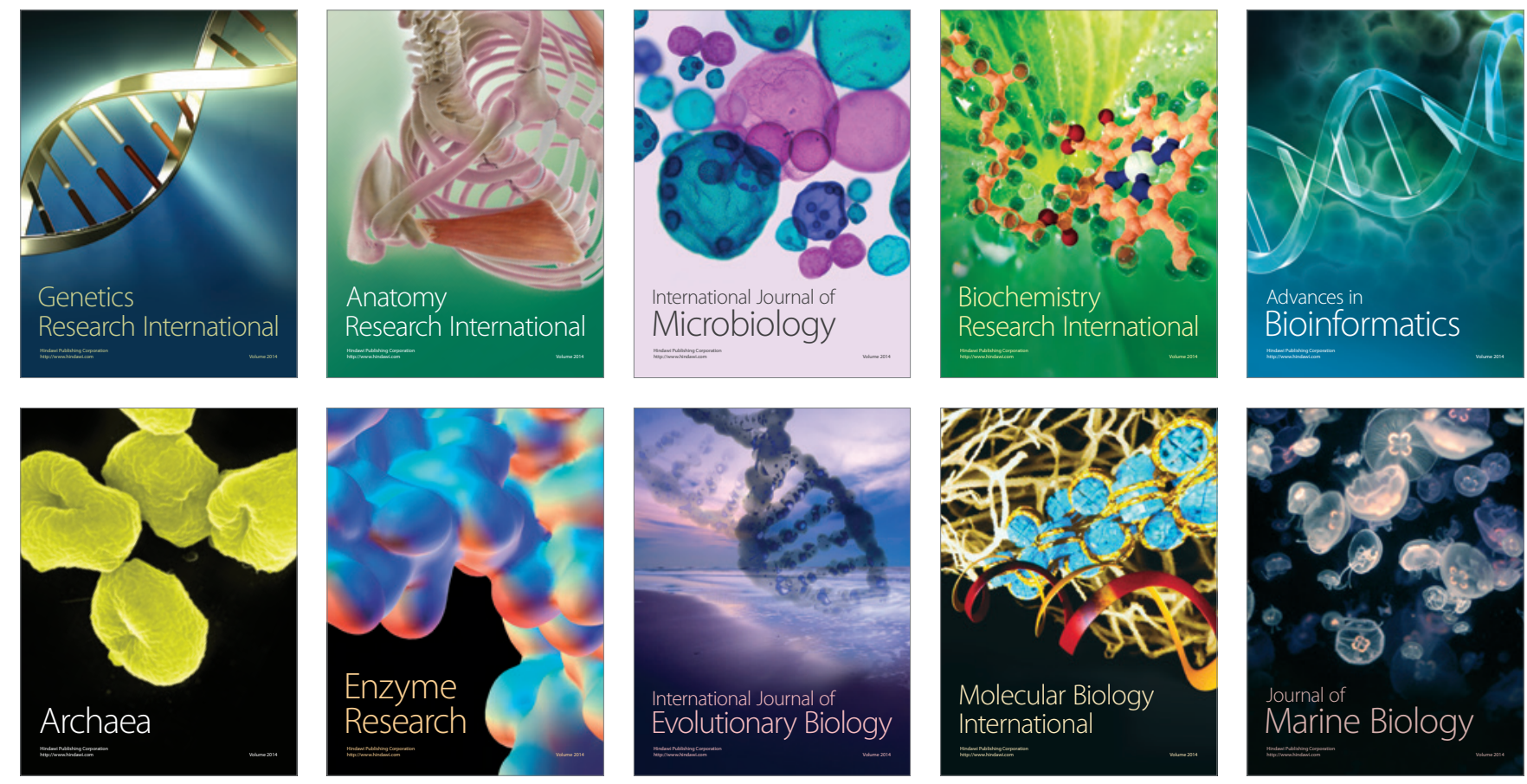